\title{
Viability of Optical Scanning Techniques for Digitization of Lower Limbs
}

\author{
A Horta ${ }^{1,3}$, M Borges ${ }^{1,4}$, M Volpini ${ }^{1 *}$ and P Reis ${ }^{1,2}$ \\ ${ }^{1}$ Oh Lab, Associação Mineira de Reabilitação, Belo Horizonte, Brazil \\ ${ }^{2}$ Universidade Federal de Minas Gerais, Department of Industrial Engineering, Brazil \\ ${ }^{3}$ Universidade do Estado de Minas Gerais, Escola de Design, Brazil \\ ${ }^{4}$ Universidade do Federal de Minas Gerais, Department of Electrical Engineering, Brazil
}

Submission: May 20, 2017; Published: June 14, 2017

"Corresponding author: M Volpini, Oh Lab, Associação Mineira de Reabilitação, Belo Horizonte, Brazil, Email: marivolpini@yahoo.com.br

\begin{abstract}
When it comes to the development of customized orthopedic products that fit the patient's anatomy the measurement capture method is a constant challenge. Therefore, the measuring instrument must have high accuracy. Considering this context, the three-dimensional digitization methods are helpful tools for the capture of complex measurements and geometries. The advantages and limitations of each scanning method will determine the fidelity in data capture and the dimensional singularities of the object to be scanned. This paper aims to validate and determine the precision of optical scanning tools in support of orthopedics. They were evaluated here as digitization techniques of photogrammetry and structured light for the representation of the patient's anatomy. As result a comparative study between the dimensional deviation of the digital 3D models and the actual limb is made. The obtained results evidenced greater dimensional and geometric fidelity of the digital model generated by scanning through structured light.
\end{abstract}

Keywords: Scanning methods, photogrammetry, structured light, orthopedic devices

\section{Introduction}

Aiming the proper development of customized orthopedic products, the anatomy of the patient's limb is a fundamental factor for the correct functioning and suitability of the device to be developed [1]. The dimensions and geometry of the model that will serve as reference for the manufacture of the device must be measured with a high accuracy, making the device personalized and more efficient for the treatment and adhesion of the patient $[1,2]$.

In this context of high metrological complexity, the computational models obtained from three- dimensional scanning devices prove to be of a high-impact in terms of assistance in preoperative planning, conceptual communication among physicians and support for the development of personalized devices such as orthotics and prostheses $[3,4]$. The accuracy achieved by the models produced by threedimensional technologies is determined by the data acquisition devices, varying according to the scanning objectives and the environment to which the scanning is performed [5].

The evolution of optical technology has allowed accurate and detailed reconstruction of the geometry of real objects to become a more common and simplified process. Understanding the processes of acquisition of the virtual model by optical technologies, its limitations, advantages and disadvantages, is essential to guarantee the efficiency of the process [6]. In order to assess the quality of the digital models generated by optical scanning technologies, this study seeks to compare the scanning methods by Photogrammetry and Structured Light. The central objective is to test the feasibility of two optical scanning methods for the production of orthopedic devices through the dimensional fidelity analysis of the patient's limb.

\section{Experimental procedure}

For the accomplishment of this study the object of the scanning was the morphology of the foot of an adult male. The scanning was done respecting favorable conditions, compatible with the equipment of digitization used. Tendon and points of bone prominence were used to analyze and compare the dimensions and geometry of the foot. The marks were placed on the first and fifth metatarsals and on the medial and lateral malleolus. The object of study, as well as the layout of the marks can be visualized in Figure 1. 


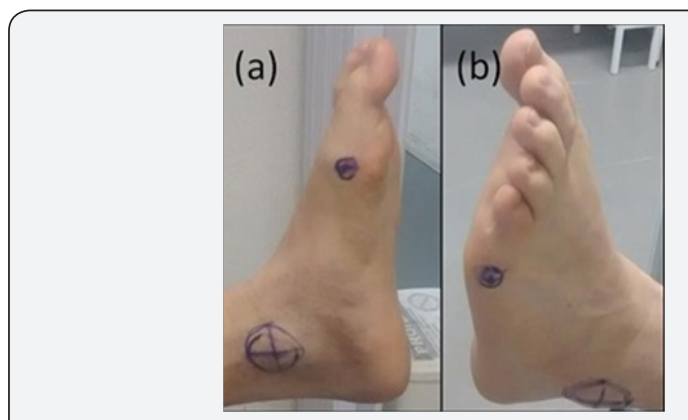

Figure 1: markers of bone prominence used; (A) Medial Malleolus and First Metatarsus; (B) Lateral Malleolus and Fifth Metatarsus.

The models generated by the scanning methods will be evaluated according to six dimensional indicators, which are: the distance between the first and fifth metatarsals, the size of the head of the first metatarsus, the center of the medial malleolus to the ground, the distance between the medial malleolus and the lateral malleolus, the distance between the lateral malleolus to the calcaneus tendon and the distance between the medial malleolus and the calcaneus tendon. The original distances specified by this study as reference are shown in Table 1.

Table 1: Distances referenced in the foot of the study patient.

\begin{tabular}{|c|c|}
\hline Reference & Distance - mm \\
\hline First to the Fifth Metatarsus & 99,5 \\
\hline Head of the First Metatarsus & 41,3 \\
\hline Medial Malleolus Center to Ground & 90,2 \\
\hline Medial Malleolus to the Lateral Malleolus & 75,4 \\
\hline Malleolus Medial to the tendon heel & 65,2 \\
\hline Malleolus Lateral to the heel tendon & 56,1 \\
\hline
\end{tabular}

The scanning of limb morphology was performed using Autodesk ReMake software, which uses the photogrammetry technique to capture the digital model and the Intel 3D Sense equipment, which uses the structured light pattern technique for execution of the virtual model. For the development of the virtual model by the photogrammetry method was used 70 digital photographs generated by a 9 megapixel camera of a smartphone model Moto G1 XT1036.

\section{Results and Discussion}

As expected, the scans performed by this research, because they were based on optical scanning techniques, presented requirements regarding the incidence of ambient light. The scanning tests were performed with uniform incident light, taking into account the necessary scanning conditions.
The method of digitalization by photogrammetry resulted in a digital model demonstrating geometric deviations in the structure of the virtual mesh when compared to the original member. The generated model presented low capture of details and low geometric complexity, demonstrating little morphological fidelity with the foot of the patient. The model, as well as the indications of the distances taken, can be visualized in Figure 2.

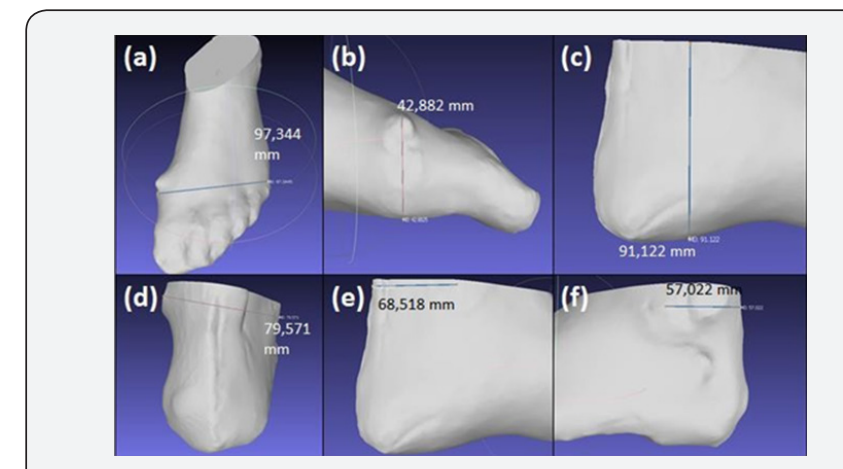

Figure 2: model generated by photogrammetry; (a) distance between the first and fifth metatarsals;

(b) dimension of the head of the first metatarsus; (c) medial malleolus center to ground; (d) the distance between the medial malleolus and the lateral malleolus; (e) distance between the lateral malleolus and the calcaneus tendon; (f) distance between the medial malleolus and the calcaneustendon.

The measured dimensions for the model generated by the geometry method presented greater percentage variation when compared to the original model. The measured distances, as well as the percentage of variation are shown in Table 2.

Table 2: Measured reference distances of the model generated by photogrammetry, and percentage of variation with original model.

\begin{tabular}{|c|c|c|}
\hline Reference & $\begin{array}{c}\text { Distance - } \\
\text { mm }\end{array}$ & $\begin{array}{c}\text { Percentage } \\
\text { Change }\end{array}$ \\
\hline First to the Fifth Metatarsus & 97,34 & $2,17 \%$ \\
\hline Head of the First Metatarsus & 42,88 & $3,83 \%$ \\
\hline $\begin{array}{c}\text { Medial Malleolus Center to } \\
\text { Ground }\end{array}$ & 91,12 & $1,02 \%$ \\
\hline $\begin{array}{c}\text { Medial Malleolus to the Lateral } \\
\text { Malleolus }\end{array}$ & 79,57 & $5,53 \%$ \\
\hline $\begin{array}{c}\text { Malleolus Medial to the tendon } \\
\text { heel }\end{array}$ & 68,51 & $5,08 \%$ \\
\hline $\begin{array}{c}\text { Malleolus Lateral to the heel } \\
\text { tendon }\end{array}$ & 57,02 & $1,64 \%$ \\
\hline
\end{tabular}

The model generated by the structured light scanning method presented high geometric detail capture and high dimensional fidelity with the original model, although it 
presented a higher noise index when compared to the model generated by photogrammetry. The detail capture was high, accurately representing the geometric contours of the patient's foot. The model, as well as the distance indications taken, can be visualized in Figure 3.

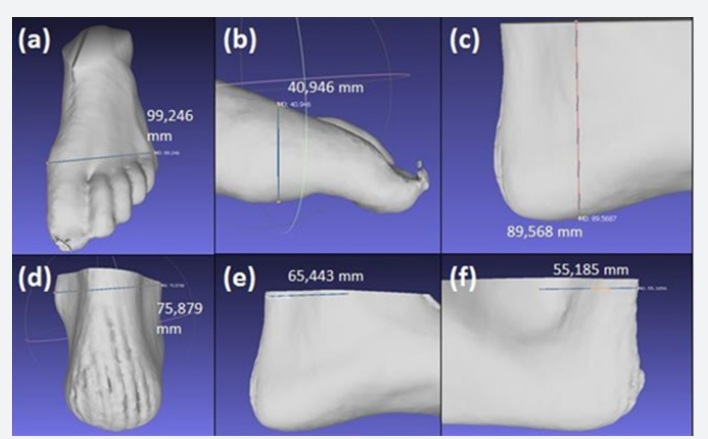

Figure 3: model generated by structured light; (a) distance between the first and fifth metatarsals;

(b) dimension of the head of the first metatarsus; (c) medial malleolus center to ground; (d) the distance between the medial malleolus and the lateral malleolus; (e) distance between the lateral malleolus and the calcaneus tendon; (f) distance between the medial malleolus and the calcaneustendon.

The reference dimensions of the model generated by structured light presented greater fidelity to the original model, with low percentage variation. The measured distances, as well as the percentage of variation are shown in Table 3.

Table 3: Measured reference distances of the model generated by structured light, and percentage of variation with original model.

\begin{tabular}{|c|c|c|}
\hline Referencia & $\begin{array}{c}\text { Distance - } \\
\text { mm }\end{array}$ & $\begin{array}{c}\text { Percentage } \\
\text { Change }\end{array}$ \\
\hline First to the Fifth Metatarsus & 99,24 & $0,26 \%$ \\
\hline $\begin{array}{c}\text { Head of the First Metatarsus } \\
\text { Medial Malleolus Center to } \\
\text { Ground }\end{array}$ & 40,94 & $0,87 \%$ \\
\hline $\begin{array}{c}\text { Medial Malleolus to the Lateral } \\
\text { Malleolus }\end{array}$ & 75,87 & $0,71 \%$ \\
\hline $\begin{array}{c}\text { Malleolus Medial to the tendon } \\
\text { heel }\end{array}$ & 65,44 & $0,62 \%$ \\
\hline $\begin{array}{c}\text { Malleolus Lateral to the heel } \\
\text { tendon }\end{array}$ & 55,18 & $1,64 \%$ \\
\hline
\end{tabular}

Considering the dimensional topography of the two models, the most latent differences were evidences in bone prominences of greater dimensional significance, such as the medial malleolus and the first metatarsus. The dimensional comparison between the two models presented greater variation in the size of the medial malleolus, with an error of $14.94 \mathrm{~mm}$. The average dimensional error between the two models was $1.01 \mathrm{~mm}$. The dimensional variation and distance histogram can be visualized in Figure 4.
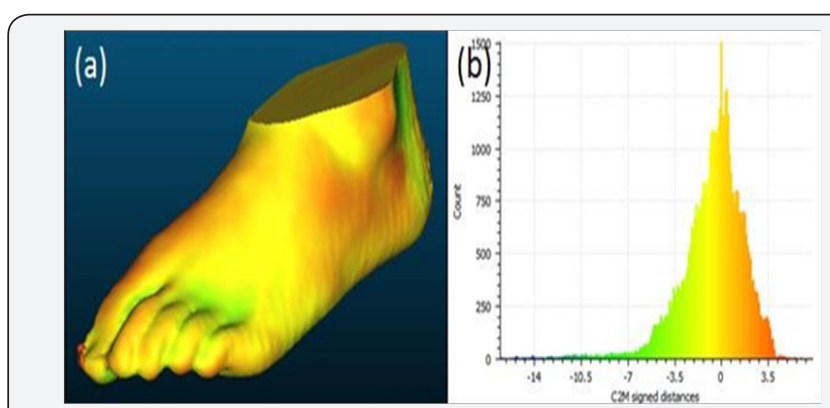

Figure 4: dimensional comparison between the models generated by photogrammetry and structured light; (a) dimensional topography; (b) histogram of mean distances.

\section{Conclusion}

The results demonstrated by this study show the feasibility of the three-dimensional optical data capture procedures to aid in orthopedic demands. The precision of the models generated by the scanning techniques presented few dimensional variations when compared to the original member. Although the two models generated presented viability in the context of diagnostic assistance and the manufacture of orthopedic devices, the model that came closest to the observed reality was the model generated by scanning through structured light.

\section{References}

1. Hawke F, Burns J, Radford JA, du Toit V (2008) Custom-made foot orthoses for the treatment of foot pain. Cochrane Database Syst Rev 16(3): CD006801.

2. Trotter LC, Pierrynowski MR (2008) Ability of foot care professionals to cast feet using the non- weightbearing plaster and the gait-referenced foam casting techniques. JAPMA 98(1): 14-18.

3. Helule K, Coole T, Chesire D (2000) Fabrication of medical models from scan data via rapid prototyping techniques. Proceedings of the 2000 Conference on Time Compression Technologies Cardiff International Arena, UK.

4. Ieu LC, Zlatov N, Sloten JV, Bohez E, Khanh L, (2005) Medical rapid prototyping: applications and methods. Assembly Automation 25(4): 284-292.

5. Raja I, Fernandes VJ (2008) Reverse engineering: an industrial perspective. London.

6. Wego W (2011) Reverse engineering: Technology of Reinvention, CRC Press-Taylor \& Francis, Florida, USA. 
This work is licensed under Creative Commons Attribution 4.0 License

DOI: $10.19080 /$ CTBEB.2017.05.555659

\section{Your next submission with Juniper Publishers} will reach you the below assets

- Quality Editorial service

- Swift Peer Review

- Reprints availability

- E-prints Service

- Manuscript Podcast for convenient understanding

- Global attainment for your research

- Manuscript accessibility in different formats ( Pdf, E-pub, Full Text, Audio)

- Unceasing customer service

Track the below URL for one-step submission https://juniperpublishers.com/online-submission.php 